\title{
Geomorfologia e Geodiversidade do litoral piauiense para fins de Geoconservação
}

\author{
Geomorphology and Geodiversity of Piaui coast for Geoconservation purposes
}

\author{
Baptista $^{1}$, E. M. C.; Moura ${ }^{1}$, L. S.; Silva ${ }^{2}$, B. R. V. \\ baptistaeli@gmail.com;
}

\begin{abstract}
Resumo
Este trabalho tem como objetivo relacionar os aspectos geomorfológicos do litoral piauiense e seu valor para geodiversidade visando seu conhecimento e divulgação. Para esta pesquisa foram consideradas as discussões sobre geodiversidade e geomorfologia litorânea. Como procedimentos metodológicos foram empregados a pesquisa bibliográfica e de campo, utilizando técnicas da observação sistemática para identificação e descrição das feições geomorfológicas, registro fotográfico e materiais como caderneta de campo, cartas planialtimétricas, GPS de navegação e câmera digital. As observações da paisagem e morfologia, conferidas com informações do estudo bibliográfico subsidiaram a identificação e descrição de feições geomorfológicas representativas para a geodiversidade do litoral piauiense, a saber: planícies fluviais, planícies lacustres, planícies flúvio-marinhas, praias, campos de dunas, estuários e delta. Com predomínio de formas litorâneas, representadas por suas praias, sistemas fluviais, campos de dunas e/ou agrupamento de rochas, os exemplos da geomorfologia do litoral do Piauí compõem sua geodiversidade carecendo de serem valorizados e divulgados para fins de geoconservação.
\end{abstract}

Palavras-chave: Geodiversidade. Geomorfologia Litorânea. Litoral Piauiense.

\begin{abstract}
This paper aims to relate the geomorphological aspects of Piauí coast and its value to geodiversity aiming their knowledge and dissemination. For this research was considered the discussions on geodiversity and the coastal geomorphology. As methodological procedures was used bibliographical and field research using techniques of systematic observation to identify and to describe the geomorphological features, photographic record and materials such as field book, planialtimetrics cards, navigation GPS and digital camera. The observations of the landscape and morphology, conferred with bibliographical study supported the identification and description of representative geomorphological features for Piauí's coast geodiversity, namely: river plains, lake plains, fluvial-marine plains, beaches, dune fields, estuaries and delta. With a predominance of coastal forms, represented by its beaches, fluvial systems, dune fields and/or grouping of rocks, the geomorphology examples of Piauís coast are configured as its geodiversity lacking to be valued and disclosed for geoconservation purposes.
\end{abstract}

Keywords: Geodiversity. Coastal geomorphology. Piauí's coast.

\section{INTRODUÇÃO}

Compreendida como o conjunto dos elementos geológicos e geomorfológicos que expressam valores para a geoconservação, a geodiversidade tem sido discutida de forma mais reservada para os ambientes litorâneos.

A Geodiversidade se expressa, segundo Gray (2004), como a variedade natural de aspectos geológicos (minerais, rochas e fósseis), geomorfológicos (formas de relevo, processos) e pedológicos, abrangendo suas coleções, relações, propriedades, interpretações e sistemas. O autor

\footnotetext{
${ }^{l}$ Elisabeth Mary de Carvalho Baptista, Coordenação do Curso de Geografia/Núcleo de Estudos sobre a Zona Costeira do Estado do Piaui-NEZCPI, Universidade Estadual do Piauí - UESPI, Teresina-PI, Brasil

${ }^{1}$ Liége de Souza Moura, Coordenação do Curso de Geografia/Núcleo de Estudos sobre a Zona Costeira do Estado do PiauíNEZCPI, Universidade Estadual do Piauí - UESPI, Teresina-PI, Brasil

${ }^{2}$ Brenda Rafaele Viana da Silva, Núcleo de Estudos sobre a Zona Costeira do Piauí - NEZCPI, Universidade Estadual do Piauí, Teresina-PI, Brasil
} 
indica ainda que sem ela biodiversidade seria em menor proporção evidenciando a necessidade de uma abordagem integrada para a conservação da natureza e gestão sustentável da terra.

Medeiros, Assis e Meneses (2011, p. 1) afirmam "que a Geodiversidade é como uma autobiografia do planeta Terra, pois dela podem ser obtidas as informações sobre a evolução do planeta $[\ldots]$ "escritas" por ela mesma $[\ldots]$ ".

Soldateli, Barboza e Rosa (2011) atestam que, para o setor costeiro, estudos que se relacionam tanto com a biodiversidade como com a geodiversidade ainda são poucos, destacando-se os focados na biodiversidade e ao se referirem à geodiversidade informam que os trabalhos geralmente são em escala regional.

A Geoconservação corresponde a um novo paradigma ou corrente de pensamento voltado para o meio natural e sua conservação. Sua abordagem relaciona-se com a proteção e conservação da natureza, considerando o valor científico, pedagógico, cultural, turístico ou outros, das ocorrências geológicas características de determinados lugares e que devem ser conservadas (PEREIRA; BRILHA; GOMES, 2009). Essas ocorrências geológicas e também geomorfológicas agregadas a elementos edáficos compõem a geodiversidade, que dão sentido à geoconservação.

No Piauí, estado da região Nordeste do Brasil, os estudos relativos à geodiversidade do litoral ainda são incipientes, o que evidencia a necessidade de se investir em pesquisas que possam identificar esses atributos e somar a outras possibilidades, como a geoconservação na proteção dos recursos litorâneos do estado. Com a menor extensão dentre a costa brasileira, o litoral piauiense, entretanto é caracterizado por uma diversidade natural de aspectos geológicos e geomorfológicos que justifica a necessidade de se estabelecer e aprofundar pesquisas relacionadas à sua geodiversidade.

O objetivo deste trabalho é relacionar os aspectos geomorfológicos do litoral piauiense e seu valor para geodiversidade visando seu conhecimento e divulgação para fins da geoconservação, a partir das discussões sobre geodiversidade e geomorfologia litorânea que se constituem como indicadores para esta diversidade.

\section{METODOLOGIA}

Tratando-se de uma pesquisa descritiva sob a perspectiva de seu objetivo, pois o pesquisador somente registra e descreve os fatos que observou não interferindo neles (PRODANOV; FREITAS, 2013), os procedimentos metodológicos para o desenvolvimento da investigação incluíram a pesquisa bibliográfica, que se configura na utilização de livros, revistas entre outras fontes, para realização da discussão teórica da temática estudada (ALVES; CUSTÓDIO, 2011) e a pesquisa de 
campo, utilizando a técnica da observação sistemática de campo, focada em alvos determinados pelo objetivo da investigação, dependendo da abordagem da ciência que está conduzindo o estudo, utilizando instrumentos diversos para sua operacionalização e registro (VENTURI, 2011). Para identificação das feições geomorfológicas do litoral piauiense e respectivo registro fotográfico foram utilizados o roteiro de observação, mapas e cartas planialtimétricas, GPS de navegação e câmera digital.

A pesquisa bibliográfica possibilitou então a compreensão sobre as características das feições geológicas e geomorfológicas do litoral piauiense, auxiliando a identificação e descrição realizada através da observação.

Para a descrição das feições tomou-se como premissa as descrições já elaboradas por autores como Cavalcanti e Camargo (2002), Suguio (2003), Suertegaray (2008), Baptista (2010) e Guerra e Guerra (2011) e a pesquisa desenvolveu-se a partir de duas etapas, a saber:

a. Trabalho de gabinete, compreendendo as atividades de reconhecimento e levantamento geral da área através de material cartográfico e pesquisa bibliográfica sobre as feições litorâneas e estudos já realizados sobre o litoral piauiense relacionados à temática.

b. Trabalho de campo, visando identificar e realizar a descrição das feições litorâneas piauienses complementando o estudo realizado em gabinete.

\section{GEOMORFOLOGIA E GEODIVERSIDADE DO LITORAL PIAUIENSE}

A geomorfologia costeira trata da construção das feições da costa, dos processos que nela atuam e das mudanças que sobre ela ocorrem (BIRD, 2008), tendo como suporte os aspectos geológicos costeiros como formações rochosas e os sedimentos depositados nessas áreas no decorrer do tempo. Deste modo, a dinâmica natural das regiões costeiras se organiza em uma imbricada inter-relação entre os elementos de sua geodiversidade, como rochas, minerais, solos, formas de relevo etc.

O litoral piauiense situa-se entre as coordenadas geográficas $2^{\circ} 42^{\prime} 35^{\prime}$ e e $3^{\circ} 05^{\prime} 02^{\prime \prime}$ de latitude sul e $41^{\circ} 14^{\prime} 53^{\prime \prime}$ e $41^{\circ} 52^{\prime} 46^{\prime \prime}$ de longitude oeste (figura 01), compreendendo aproximadamente 1.200

$\mathrm{km}^{2}$, limitado a leste pelo estado do Ceará e a oeste pelo estado do Maranhão, sendo o de menor extensão da costa brasileira, com $66 \mathrm{~km}$, representando apenas 0,89\% do território nacional (BAPTISTA, 2010). Geologicamente está embasado por sedimentos da Formação Barreiras, recobertos por depósitos do Quaternário (BAPTISTA, 2010), contribuindo para a configuração de suas feições geomorfológicas. 


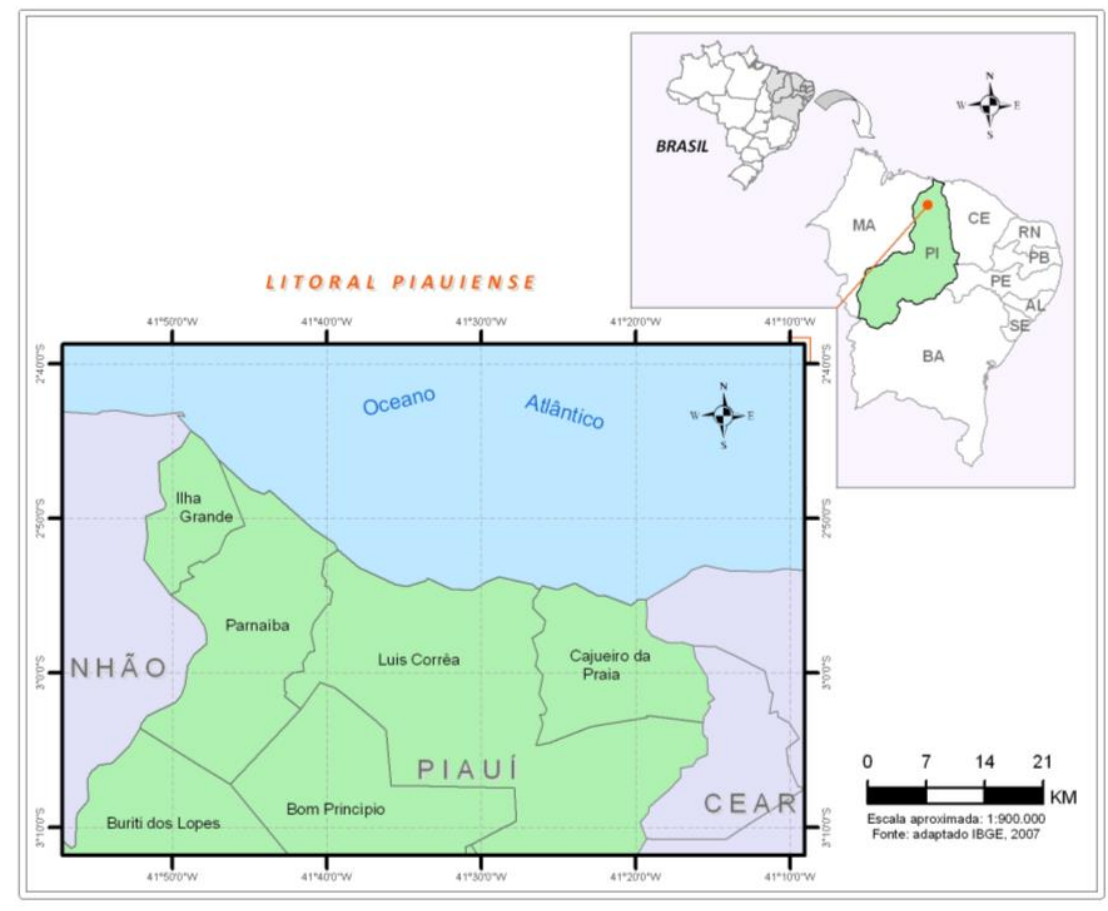

Figura 01. Localização geográfica do litoral piauiense Fonte: Baptista (2010)

A faixa litorânea piauiense se insere na Área de Proteção Ambiental Delta do Parnaíba, Unidade de Conservação criada em 1996, com o objetivo principal de proteger as áreas de desembocadura dos rios Parnaíba, Ubatuba e Timonha e apresenta quatro municípios costeiros, Cajueiro da Praia, Luís Correia, Parnaíba e Ilha Grande (BRASIL, 1998).

Nesta pesquisa, foram identificadas no litoral piauiense feições geomorfológicas representativas para a geodiversidade local, destacando-se as planícies fluviais, planícies lacustres, planícies flúvio-marinhas, praias, campos de dunas, estuários e delta.

Para descrição das feições identificadas recorreu-se a observação sistemática e o estudo bibliográfico em trabalhos relacionados à geomorfologia, geomorfologia costeira e ao litoral do Piauí, como segue.

\subsection{Geodiversidade e Feições geomorfológicas}

As Planícies fluviais constituem-se áreas de sedimentação fluvial formadas nas margens dos rios, periodicamente sujeitas a inundações (SUERTEGARAY, 2008). No litoral piauiense, apresentam-se de forma geralmente planas constituindo faixas de aluviões e/ou baixadas inundáveis, associadas também às lagoas (BAPTISTA, 2010), compreendendo as áreas de inundação dos rios Parnaíba, Igarassú, Cardoso/Camurupim e Ubatuba (CAVALCANTI; 
CAMARGO, 2002). Existem ainda inúmeros outros riachos que contribuem para a formação dessas planícies, em sua maioria tributários dos citados rios.

As Planícies lacustres são depressões de pequenas profundidades, com formas variadas, especialmente circulares (GUERRA; GUERRA, 2011), de água salgada, doce ou salobra, sendo que no litoral piauiense predomina lagoas de água doce e em sua maioria relacionadas a cursos de águas fluviais, como as do Portinho, Santana e Camelo. Diferencia-se destas a lagoa do Sobradinho por ser de água salgada, por sua origem residual ou reliquiar (SUGUIO, 2003), apresentando forma que se assemelha a uma ferradura. Outra lagoa que se destaca no litoral piauiense é a do Camelo, por existirem em seu leito afloramentos rochosos cuja forma é semelhante a corcovas do citado animal, de onde decorre a denominação.

Em se tratando das Planícies flúvio-marinhas, estas apresentam constituição de "sedimentos lanosos orgânicos, argilas plásticas e fragmentos vegetais, típicos de pântanos, alagados e regiões semi-submersas de água doce ou salobra" (BAPTISTA, 2010, p. 151), correspondendo às áreas de manguezais, encontradas nas zonas de influência das marés, relacionadas com os cursos d'aguas e com as lagoas das áreas nas planícies dos rios Parnaíba, Igarassú e Cardoso (CAVALCANTI; CAMARGO, 2002), denominadas também como alagados de maré, salgados ou apicuns.

As Praias, feições mais comuns no litoral do Piauí, são faixas de superfície arenosa decorrentes da acumulação marinha, que delineiam a linha de costa, podendo formar cordões litorâneos em vários trechos do litoral piauiense, sendo em alguns deles associado a dunas (BAPTISTA, 2010). A maioria das praias piauiense é desprovida de outras feições que não a areia e por vezes as dunas, mas em algumas estão expostas rochas de praia (beachrocks), recifes de arenito, geralmente associados à Formação Barreiras e afloramentos de rochas graníticos. Dentre elas, as mais conhecidas são as de Atalaia, Coqueiro, Barra Grande e Pedra do Sal.

Os Campos de dunas são formas de relevo resultante da acumulação de depósitos eólicos dispostos ao longo da linha de costa piauiense, constituídos por areia fina quartzosas, de coloração esbranquiçada com tons amarronzados e amarelados muito claros, apresentando-se móveis, semifixos e fixos em feições longitudinais e transversais, com altitude variada (CAVALCANTI; CAMARGO, 2002; BAPTISTA, 2010). Estão presentes desde o Delta do rio Parnaíba, ao longo das faixas de praia e por toda a planície costeira.

Os Estuários são áreas das desembocaduras de cursos d'água no oceano que se caracterizam por uma abertura larga, relativamente profunda (SUERTEGARAY, 2008). Formando uma única entrada ou boca, em oposição ao delta, não acumulam sedimentos pela influência das correntes marinhas e de maré (GUERRA; GUERRA, 2011). No litoral piauiense os cursos fluviais apresentam pelo menos três formas diferentes de desembocaduras: em um único canal como na 
maioria dos pequenos riachos, como a barra dupla dos rios Ubatuba-Timonha, que são rios independentes, mas se encontram e juntos se direcionam a sua foz, e em forma de delta, no caso o rio Parnaíba, que desemboca no Oceano Atlântico através de cinco canais.

O Delta, configuração especial de desembocadura de curso fluvial, se constitui em uma forma de deposição de sedimentos fluviais que pode se apresentar em formato de leque, ou seja, dividindo-se em canais múltiplos, ou lembrando a letra grega delta (SUERTEGARAY, 2008), daí decorrendo sua denominação. O delta do rio Parnaíba é uma das feições geomorfológicas típicas do litoral piauiense, embora entre as cinco barras ou canais que se direcionam ao Oceano Atlântico, somente a do rio Igarassú esteja no estado do Piauí. Este complexo deltaico possui ainda inúmeros igarapés, ilhas, manguezais, lagoas interdunares e campos de dunas. "Trata-se da única feição deltaica das Américas, localizada em mar aberto" (BRASIL, 1998, p.25).

O quadro 1 e figura 2 apresentam o registro das feições identificadas e sua localização.

Quadro 01. Feições geomorfológicas no litoral do Piauí. Fonte: Baptista, Moura e Silva (2016)

\begin{tabular}{|c|c|c|c|}
\hline \multirow{2}{*}{ Feição } & \multicolumn{2}{|c|}{ Coordenadas Geográficas } & \multirow{2}{*}{ Localização } \\
\hline & Latitude $\mathrm{S}$ & Longitude W & \\
\hline Planície fluvial (A) & $3^{\circ} 4^{\prime} 41,1^{\prime \prime}$ & $41^{\circ} 15^{\prime} 17,5$ & Rio Ubatuba - Luís Correia \\
\hline Planície lacustre (B) & $2^{\circ} 56^{\prime} 37,5^{\prime \prime}$ & $41^{\circ} 31^{\prime} 57,9^{\prime \prime}$ & Lagoa do Sobradinho - Luís Correia \\
\hline Planície flúvio-marinha $(\mathrm{C})$ & $2^{\circ} 54^{\prime} 36,6^{\prime \prime}$ & $41^{\circ} 26^{\prime} 51^{\prime \prime}$ & Rio Cardoso - Luís Correia \\
\hline Praia (D) & $2^{\circ} 55^{\prime} 35,4^{\prime \prime}$ & $41^{\circ} 20^{\prime} 9,6^{\prime \prime}$ & $\begin{array}{c}\text { Praia de Cajueiro da Praia - } \\
\text { Cajueiro da Praia }\end{array}$ \\
\hline Campo de dunas (E) & $2^{\circ} 54^{\prime} 18,9^{\prime \prime}$ & $41^{\circ} 35^{\prime} 29,8^{\prime \prime}$ & Planície Costeira - Luís Correia \\
\hline Estuário (F) & $2^{\circ} 55^{\prime} 35^{\prime \prime}$ & $41^{\circ} 29^{\prime} 53,6^{\prime \prime}$ & Riacho Lagoa Doce - Luís Correia \\
\hline $\operatorname{Delta}(\mathrm{G})$ & $2^{\circ} 49^{\prime} 52,7^{\prime \prime}$ & $41^{\circ} 49^{\prime} 47,7^{\prime \prime}$ & Rio Parnaíba - Ilha Grande \\
\hline
\end{tabular}
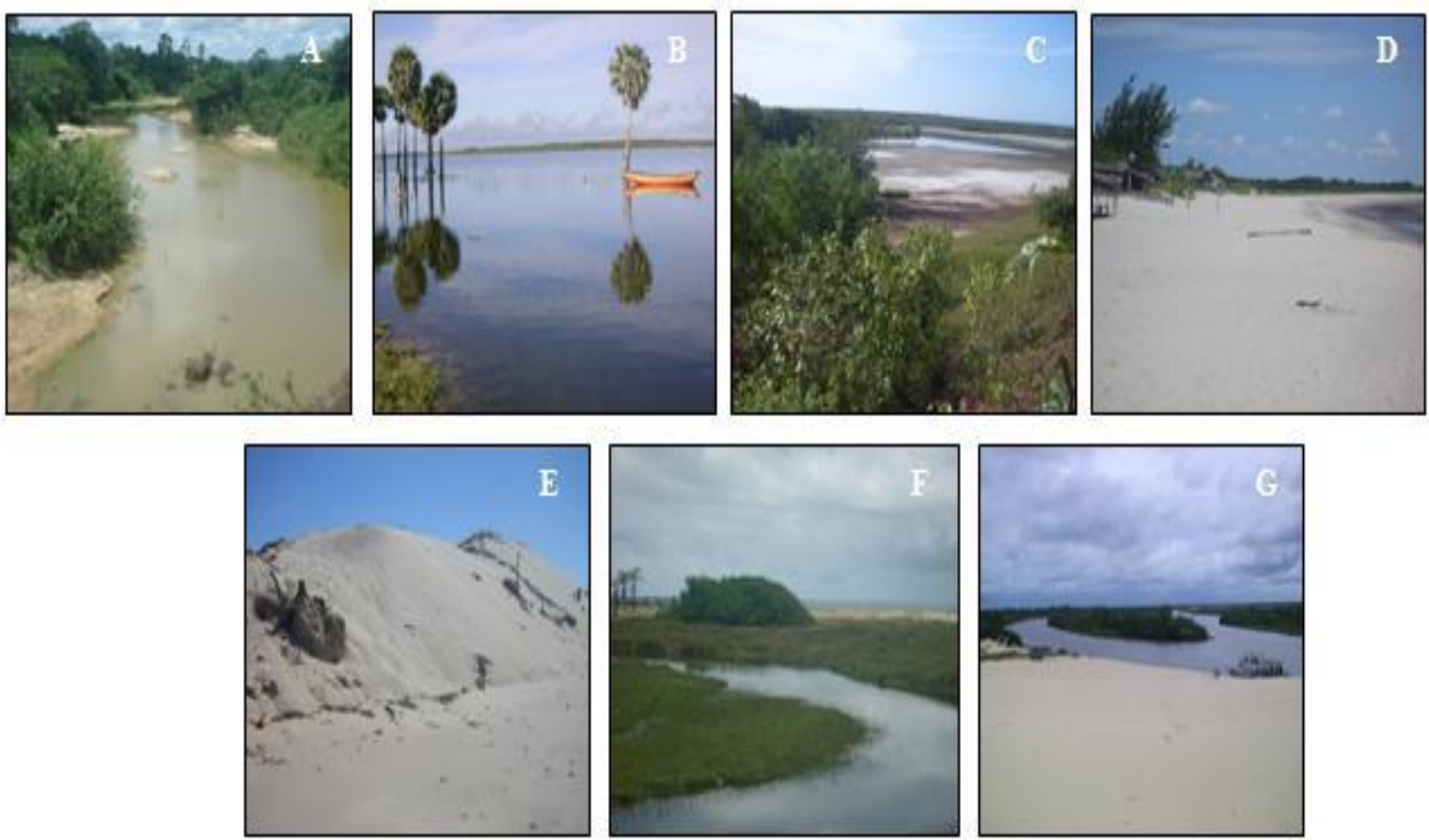

Figura 02. Feições geomorfológicas no litoral do Piauí. Fonte: Baptista, Moura e Silva (2016) 


\section{CONSIDERAÇÕES FINAIS}

Os estudos que tratam sobre a geomorfologia do litoral do Piauí, como elemento para a geodiversidade e para fins de geoconservação ainda são recentes, com destaque para o livro sobre a geodiversidade do estado como um todo organizado por Pfaltzgraff, Torres e Brandão (2010) e os trabalhos de Baptista, Silva e Moura (2014) e Silva e Baptista (2014 a, b), que discutem a possibilidade de desenvolvimento da geoconservação, tendo o patrimônio geomorfológico e sua geodiversidade como indicador para esse processo.

No aspecto geomorfológico o litoral piauiense apresenta predominantemente formas litorâneas representadas por suas praias e sistemas estuarinos e/ou agrupamento de rochas. Destacam-se ainda as formações de planícies relacionadas aos cursos fluviais, campos de dunas e às lagoas existentes, bem como o delta do rio Parnaíba, feição geomorfológica ímpar para a região.

Estas formas se configuram em pelo menos sete aspectos geomorfológicos diferenciados na paisagem compondo assim os atributos geomorfológicos para a geodiversidade local. Deste modo sua valorização enquanto formas distintas no litoral piauiense reforça a necessidade de sua proteção e conservação objetivando a geoconservação.

\section{REFERÊNCIAS}

ALVES, G. A.; CUSTÓDIO, V. Uso e Registro de Fontes Bibliográficas. In Geografia: práticas de campo, laboratório e sala de aula. São Paulo: Sarandi, 2011. 528 p.

BAPTISTA, E. M. C.; SILVA, B. R. V.; MOURA, L. S. Patrimônio Natural e Perspectivas para a Geoconservação no Litoral do Estado do Piauí Brasil. In ENCONTRO LUSO-BRASILEIRO DE PATRIMÓNIO GEOMORFOLÓGICO E GEOCONSERVAÇÃO, 1. Atas / Proceedings. APOGEO, Coimbra - Portugal, 2014.

BAPTISTA, E. M. C. Estudo morfossedimentar dos recifes de arenito da zona litorânea do estado do Piauí, Brasil. Tese de Doutorado, Universidade Federal de Santa Catarina - UFSC, Florianópolis, 2010. 305 p.

BIRD, E. C. F. Coastal geomorphology: an introduction. Chichester, England: John Wiley \& Sons Ltd, 2008. $411 \mathrm{p}$.

BRASIL. INSTITUTO BRASILEIRO DO MEIO AMBIENTE E DOS RECURSOS NATURAIS RENOVÁVEIS - IBAMA. Plano de Gestão e Diagnóstico Geoambiental e Sócio-econômico da APA Delta do Parnaíba. Fortaleza: IEPS/UECE, 1998. 101 p. 
CAVALCANTI, A. P. B.; CAMARGO, J. C. G. Impactos e condições ambientais da zona costeira do estado do Piauí. In Do natural, do Social e de suas Interações. Rio Claro: UNESP/AGETEO, 2002. $272 \mathrm{p}$.

GRAY, M. Geodiversity: valuing and conserving abiotic nature. Chichester, England: John Wiley \& Sons Ltd, 2004. 434 p.

GUERRA, A. T.; GUERRA, A. J. T. Novo dicionário geológico-geomorfológico. Rio de Janeiro: Bertrand Brasil, 2011. 648 p.

MEDEIROS, S. C. O.; ASSIS, H. Y. E. G.; MENESES, L. F. Mapeamento da Geodiversidade do Município de Rio Tinto - PB. In CONGRESSO DE ECOLOGIA DO BRASIL, 10. Anais. 2011. São Lourenço - MG.

PEREIRA, J. M.; BRILHA, J.; GOMES. A. M. (2009). Proposta para a promoção do património geológico e da geoconservação na Conservação da Natureza de Cabo Verde. In CONGRESSO DE DESENVOLVIMENTO REGIONAL DE CABO VERDE, 1; CONGRESSO DE GESTÃO E CONSERVAÇÃO DA NATUREZA, 3. 2009. Actas Proceedings.... Cidade da Praia, Cabo Verde. PFALTZGRAFF, P. A.; TORRES, F. S. M.; BRANDÃO, R. L. Geodiversidade do estado do Piauí. Recife: CPRM, 2010. 260 p.

PRODANOV, C. C.; FREITAS, E. C. Metodologia do trabalho científico: métodos e técnicas da pesquisa e do trabalho. 2. ed. Novo Hamburgo: FEEVALE, 2013.

SILVA, B. R. V.; BAPTISTA, E. M. C. Geoconservação para a zona costeira piauiense: análise e proposta. In SIMPÓSIO DE PRODUÇÃO CIENTÍFICA DA UESPI, 14, SEMINÁRIO DE INICIAÇÃO CIENTÍFICA DA UESPI, 13. Livro de Resumo... Teresina: UESPI, 2014a.

SILVA, B. R. V.; BAPTISTA, E. M. C. Roteiro Geológico-Geomorfológico do Litoral Piauiense: Caminhos para a Geoconservação. Revista GEONORTE, n. 10, p. 95-98, 2014b.

SOLDATELI, A.; BARBOZA, E. G.; ROSA, M. L. C. As Relações entre a Biodiversidade e a Geodiversidade no Setor Costeiro do Parque Estadual da Itapeva, Torres, RS. In CONGRESSO DA ASSOCIAÇÃO BRASILEIRA DE ESTUDOS DO QUATERNÁRIO, 13. 2011. Anais. Armação dos Búzios, Rio de Janeiro: ABEQUA, 2011.

SUERTEGARAY, D. M. A. (Org.). Terra: feições ilustradas. 3. ed. Porto Alegre: UFRGS, 2008. $263 \mathrm{p}$.

SUGUIO, K. Geologia Sedimentar. São Paulo: Blucher, 2003. 400 p.

VENTURI, L. A. B. A Técnica e a Observação na Pesquisa. In Geografia: práticas de campo, laboratório e sala de aula. São Paulo: Sarandi, 2011. 528 p. 


\section{AGRADECIMENTOS}

Trabalho decorrente das atividades de investigação do Núcleo de Estudos sobre a Zona Costeira do Estado do Piauí - NEZCPI da Universidade Estadual do Piauí - UESPI, ao qual as autoras expressam seus agradecimentos.

Recebido em: 14/08/2016

Aceito para publicação em: 01/10/2016 